\title{
Dietary behaviour, psychological well-being and mental distress among adolescents in Korea
}

Seo Ah Hong ${ }^{1,2}$ and Karl Peltzer $3,4^{*}$ (D)

\begin{abstract}
Background: Dietary intake is important for physical and mental health. The aim of this investigation was to assess associations between dietary behaviours and psychological well-being and distress among school-going adolescents in Korea.

Methods: In a cross-sectional nationally representative survey, 65,212 students (Mean age $=15.1$ years, SE $=0.02$ and $52.2 \%$ male and $47.8 \%$ female) responded to a questionnaire that included measures of dietary behaviour, psychological well-being and mental distress.

Results: In logistic regression analyses, adjusted for age, sex, socioeconomic status, school level, school types, Body Mass Index, physical activity, and substance use, positive dietary behaviours (regular breakfast, fruit, vegetable, and milk consumption) were positively and unhealthy dietary behaviours (intake of caffeine, soft drinks, sweet drinks and fast food consumption) were negatively associated with self-reported health, happiness and sleep satisfaction. Positive dietary behaviours (regular breakfast, fruit, vegetable, and milk consumption) were negatively associated with perceived stress and depression symptoms. Unhealthy dietary behaviours (consumption of fast food, caffeine, sweetened drinks and soft drinks) were associated with perceived stress and depression symptoms.
\end{abstract}

Conclusions: The study found strong cross-sectional evidence that healthy dietary behaviours were associated with lower mental distress and higher psychological well-being. It remains unclear, if a healthier dietary behaviour is the cause or the sequela of a more positive well-being.

\section{Background}

Recently, more studies have been trying to link dietary behaviour to psychological well-being and distress [1-6]. Regular fruit, vegetable and breakfast intake (healthy dietary behaviours) have been found positively associated with self-reported health, happiness, and better sleep [1-8], and regular fruit, vegetable and breakfast intake were negatively associated with perceived stress, mental distress and depression [1-3, 9-25]. Further, specific unhealthy dietary behaviours (consumption of soft drinks, fast food, sweets and snacks, skipping breakfast,

\footnotetext{
*Correspondence: karl.peltzer@tdt.edu.vn

${ }^{3}$ Department for Management of Science and Technology Development,

Ton Duc Thang University, Ho Chi Minh City, Vietnam

${ }^{4}$ Faculty of Pharmacy, Ton Duc Thang University, Ho Chi Minh City, Vietnam

Full list of author information is available at the end of the article
}

and caffeine) were associated with unhappiness, perceived stress, mental or psychological distress, depression or poorer sleep $[5,8,19,24-36]$. Mixed results were found in relation to the consumption of milk and psychological well-being. One study found that increased milk product consumption was associated with depression [37], Meyer et al. [38] found milk consumption improves sleep quality, and Aizawa et al. [39] found that the frequency of fermented milk consumption was associated with higher Bifidobacterium counts and that patient with major depressive disorder have lower Bifidobacterium and/or Lactobacillus counts.

In a study among Iranian children and adolescents junk food consumption (such as fast foods, sweets, sweetened beverages, and salty snacks) was significantly associated with mental distress, including "worry, depression, 
confusion, insomnia, anxiety, aggression, and feelings of being worthless." [26] Fast food consumption was associated with depression among adolescent girls in Korea [32], and among Chinese adolescents, snack consumption was associated with psychological symptoms [34]. The poor nutrient content of junk or fast foods may have an effect on normal brain functioning and, thus, have an effect on negative mood via the synthesis of neurotransmitters such as serotonin [40, 41]. In a study among adolescents in Norway, a J-shaped relationship between soft drink consumption and mental distress was found [42]. The effects of soft drink or sugar consumption on mental health may be mediated through other nutritional or behavioural factors [42]. Among secondary school students in Malaysia, regular breakfast consumption was negatively associated with mild or moderate stress [23]. In a large study of adolescent school-going children $(\mathrm{N}=3071)$ from the United Kingdom, positive relationships between caffeine consumption and anxiety and depression were found [33]. It is possible that students used caffeinated products to cope with stress [33, 43].

We have limited information on the relationship between dietary behaviour, psychological well-being and mental distress among adolescents in Asia, which prompted this study. It was hypothesized that healthy dietary behaviour enhances psychological well-being and reduces mental distress, and unhealthy dietary behaviours reduce psychological well-being and increase mental distress.

\section{Methods}

\section{Data sources}

The data utilized for this study came from the 2016 12th "Korea Youth Risk Behavior Web-based Survey (KYRBS)" [44]. The KYRBS is an annual anonymous online self-reported cross-sectional survey on various health behaviours that uses a stratified cluster sampling procedure to source middle and high school students that are representative of the adolescent school population in Korea [44], more details under [44]. The online survey was administered during class after survey instructions had been given and written informed consent had been obtained [44]. In 2016, the survey included a total of 798 schools, and a total of 65,528 respondents participated, resulting in a response rate of $96.4 \%$ [44].

\section{Measures}

Three assessment measures of psychological well-being (self-rated health, happiness, and sleep satisfaction) and two questions on mental distress (perceived stress and depression symptoms) were used in this study.

Self-rated health was assessed with the question: "How healthy do you usually feel?" (Response option ranged from 1 = very healthy to $5=$ very unhealthy) [44]. Responses were dichotomized into 1 or $2=$ above average health and 3-5 = an average or below average health.

Perceived happiness was measured with the question: "How happy do you usually feel?" (Response options: (1) very happy, (2) happy, (3) average, (4) unhappy, or (5) very unhappy) [44]. Responses were dichotomized into $1-2=$ above average happiness and $3-5=$ average or below average happiness.

Sleep satisfaction was assessed with the question, "In the past 7 days, did you get adequate sleep to overcome fatigue?" (Response options ranged from $1=$ Sufficient to $5=$ Not sufficient at all) [44]. Responses were dichotomized into $1-2=$ above average sufficient sleep and $3-5=$ average or below average sufficient sleep.

Perceived stress was assessed with the question, "To what degree are you usually stressed?" (Response options arranged from $1=$ very much to $5=$ not at all) [44]. Responses were dichotomized into $1-2=$ above average stress and 3-5 = average or below average stress.

Depression symptoms were assessed with the question, "Have you experienced sadness or despair to the degree that you stopped your daily routine for the recent 12 months?" (Response option, "Yes" or "No") [44].

\section{Dietary behaviours}

To evaluate dietary behaviours, the regularity of breakfast meal time consumed over the past 7 days was surveyed with eight scales from 0 to 7 days. For food groups consumed over the past 7 days, the participants were asked the frequency of seven food groups, such as (1) soft drinks, (2) highly caffeinated drinks, (3) sweetened drinks, (4) fast food foods (such as pizza, hamburgers, or chicken), (5) fruits (not fruit juices), (6) vegetable dishes (excluding Kimchi), and (7) milk consumption during the past 7 days and the responses were from $1=$ none, $2=1-2$ times/week, $3=3-4$ times/week, $4=5-6$ times/ week, $5=$ once/day, $6=$ twice/day, and $7=3$ times or more/day [44].

\section{Control variables}

Sociodemographic variables included gender, age, geolocality (rural area, small or large city), maternal and paternal educational level, perceived socioeconomic status (SES), types of school (Boys only, girls only and mixed), school level (middle school and high school) [44].

The Body Mass Index (BMI) of students was calculated by dividing their self-reported weight in kilogrammes by their height in meters squared $\left(\mathrm{kg} / \mathrm{m}^{2}\right)$. According to age and gender, the students were categorized into "underweight $(<5$ th percentile), normal weight (5th $\leq$ BMI $<$ 85th percentile), overweight (85th $\leq$ BMI $<$ 95th percentile), and obese $(\geq 95$ th 
percentile)", following the BMI cut-off criteria set for Korean children by the 2007 Korean Growth Charts [45].

Physical activity was assessed in terms of the frequency of physical activity of $\geq 60$ min per day during the past 7 days [44]. Responses were categorised into $1=$ no days, $2=1-2$ days, and $3=3-7$ days.

Lifetime alcohol and tobacco use was measured with the questions, "Have you ever used alcohol?" and "Have you ever used tobacco?" (Response option, "Yes", "No") [44].

\section{Data analysis}

Descriptive statistics were used to present the proportion or mean of general subject characteristics and outcome variables. Logistic regression tests were performed to estimate adjusted odds ratios (ORs) and 95\% confidence intervals (CIs) after adjustment for selected covariates. Logistic regression analyses were conducted to calculate the association between the adolescents' well-being and mental distress variables as the main outcome variables and dietary behaviour variables after adjustment for covariates selected from bivariate association analysis with outcome variables. All analyses conducted took the sampling design parameters, weighting, clustering, and stratification of the study survey into account. All values were weighted according to the participant's probability of being chosen by sex-, grade-, and school typespecific distributions for the study region [46]. The "finite population correction (fpc) factor was used to avoid the overestimation, when developing variance estimates for population parameters" [47]. All statistical analyses was done by SAS 9.3 (SAS Institute, Cary, NC).

\section{Results}

\section{Sample characteristics}

The sample included 65,528 school-going adolescents (Mean age $=15.1$ years, $\mathrm{SE}=0.02$; age range 12-18 years) from Korea. More than half of the sample (52.2\%) were male, attended high school (54.6\%), and a mixed school (62.0\%). More than one-third (37.2\%) of the students perceived to have a high or high-middle socioeconomic status, 63.4 and $56.0 \%$ had a father and had a mother, respectively, with college or higher education. Overall, $17.3 \%$ of the students were overweight or obese, $31.3 \%$ engaged in $60 \mathrm{~min}$ or more physical activity 3-4 times a week, $14.8 \%$ ever smoked and $38.8 \%$ ever drank alcohol (see Table 1).

\section{Prevalence of well-being and mental distress indicators}

Regarding well-being indicators, $26.5 \%$ of the students perceived themselves to be "very healthy", $28.1 \%$ as "very happy" and $25.8 \%$ had sufficient or quite sufficient sleep satisfaction. In terms of mental distress, $37.3 \%$ of students reported somewhat or very much "perceived
Table 1 General characteristics of study participants

\begin{tabular}{|c|c|c|}
\hline & Unweighted frequency & Weighted \% \\
\hline \multicolumn{3}{|l|}{ Sex } \\
\hline Boys & 33,803 & 52.2 \\
\hline Girls & 31,725 & 47.8 \\
\hline Age (years), mean (sd) & 65,212 & $15.1(0.02)$ \\
\hline \multicolumn{3}{|l|}{ BMI } \\
\hline Thinness (< 5th percentile) & 3586 & 5.7 \\
\hline $\begin{array}{l}\text { Normal weight } \\
(5 \text { th } \leq \mathrm{BMl}<85 \text { th per- } \\
\text { centile })\end{array}$ & 48,979 & 77.0 \\
\hline $\begin{array}{l}\text { Overweight } \\
(85 \text { th } \leq \text { BMl }<95 \text { th per- } \\
\text { centile) }\end{array}$ & 2994 & 4.5 \\
\hline Obesity ( $\geq 95$ th percentile) & 8182 & 12.8 \\
\hline \multicolumn{3}{|l|}{ School } \\
\hline High school & 33,309 & 54.6 \\
\hline Middle school & 32,219 & 45.4 \\
\hline \multicolumn{3}{|l|}{ Types of school } \\
\hline Mixed & 41,445 & 62.0 \\
\hline Boys only & 12,032 & 19.3 \\
\hline Girls only & 12,051 & 18.7 \\
\hline \multicolumn{3}{|l|}{ Paternal education level } \\
\hline High school or less & 19,610 & 36.6 \\
\hline College or higher & 31,977 & 63.4 \\
\hline \multicolumn{3}{|l|}{ Maternal education level } \\
\hline High school or less & 23,497 & 44.0 \\
\hline College or higher & 28,860 & 56.0 \\
\hline \multicolumn{3}{|l|}{ Perceived socio-economic status } \\
\hline High/high-middle & 24,244 & 37.2 \\
\hline Middle & 31,056 & 47.3 \\
\hline Low-middle/Low & 10,228 & 15.6 \\
\hline \multicolumn{3}{|l|}{ Place of residence } \\
\hline Rural area & 4856 & 5.8 \\
\hline Large city & 29,046 & 43.3 \\
\hline Medium-sized city & 31,626 & 50.8 \\
\hline \multicolumn{3}{|l|}{ Physical activity ( $\geq 60 \mathrm{~min}$ ) } \\
\hline No & 23,817 & 36.8 \\
\hline $1-2 /$ week & 20,859 & 32.0 \\
\hline $3+/$ week & 20,852 & 31.3 \\
\hline Ever smoking in lifetime (yes) & 9511 & 14.8 \\
\hline $\begin{array}{l}\text { Ever alcohol drinking in } \\
\text { lifetime (yes) }\end{array}$ & 24,804 & 38.8 \\
\hline
\end{tabular}

All values are presented as weighted Mean (SD) or weighted \% as appropriate

stress", while $25.5 \%$ reported depression symptoms (see Table 2).

\section{Associations between dietary behaviours with well-being and mental distress indicators}

Tables 3 and 4 describe the bivariate associations with well-being and mental distress indicators, and Table 5 
Table 2 Prevalence of mental health among adolescents

\begin{tabular}{|c|c|c|}
\hline & Unweighted Frequency & Weighted \% \\
\hline \multicolumn{3}{|l|}{ 1. Well-being outcomes } \\
\hline \multicolumn{3}{|l|}{ Perceived health } \\
\hline Very healthy & 17,586 & 26.5 \\
\hline Healthy & 29,647 & 45.3 \\
\hline Fair & 14,223 & 21.9 \\
\hline Poor & 3846 & 6.0 \\
\hline Very poor & 226 & 0.4 \\
\hline \multicolumn{3}{|l|}{ Perceived happiness } \\
\hline Very happy & 18,992 & 28.1 \\
\hline Happy & 24,964 & 38.5 \\
\hline Fair & 16,743 & 25.8 \\
\hline Unhappy & 4102 & 6.4 \\
\hline Very unhappy & 727 & 1.1 \\
\hline \multicolumn{3}{|c|}{ Sleep satisfaction (Fatigue recovery from sleep) } \\
\hline Quite sufficient & 5413 & 7.8 \\
\hline Sufficient & 12,081 & 18.0 \\
\hline So So & 20,705 & 31.7 \\
\hline Not sufficient & 18,296 & 28.4 \\
\hline Not sufficient at all & 9033 & 14.1 \\
\hline \multicolumn{3}{|c|}{ 2. Mental distress outcomes } \\
\hline \multicolumn{3}{|l|}{ Perceived stress } \\
\hline Very much & 6513 & 10.0 \\
\hline Somewhat & 17,833 & 27.3 \\
\hline Average & 28,021 & 42.9 \\
\hline Not so much & 10,772 & 16.2 \\
\hline Not at all & 2389 & 3.6 \\
\hline \multicolumn{3}{|c|}{ Signs and symptoms of depression during the last year } \\
\hline No & 48,993 & 74.5 \\
\hline Yes & 16,535 & 25.5 \\
\hline
\end{tabular}

All values are presented as weighted $\%$

the adjusted analysis with well-being and mental distress indicators. In logistic regression analysis, adjusted for potential confounders, positive dietary behaviours (fruit and vegetable consumption, daily breakfast, milk consumption) were positively and unhealthy dietary behaviours (intake of caffeine, soft drinks, sweet drinks and fast food) were negatively associated with happiness or sleep satisfaction or self-reported health. Positive dietary behaviours (fruit and vegetable consumption, having daily breakfast, and milk consumption) were negatively associated with perceived stress and depression symptoms. Unhealthy dietary behaviours (fast food, caffeine, sweetened drinks and soft drinks consumption) were positively associated with perceived stress and depression symptoms (see Tables 3, 4, 5).

\section{Discussion}

This study found in agreement with previous studies [13] that a dose-response relationship between healthy dietary behaviours (regular fruit, vegetable, breakfast, and milk consumption) and well-being outcomes (perceived health, happiness and sleep satisfaction). In particular, the linear association with positive perceived health and happiness were stronger in fruit and vegetable consumption. A study among ASEAN university students showed a significant association but no dose-response relationship between fruits and vegetable consumption and positive self-rated health status [6]. Hoefelmann et al. [48] also found that higher fruit and vegetables consumption was associated with better sleep quality among Brazilian workers. Reasons for this finding are not clear and need further investigations. 


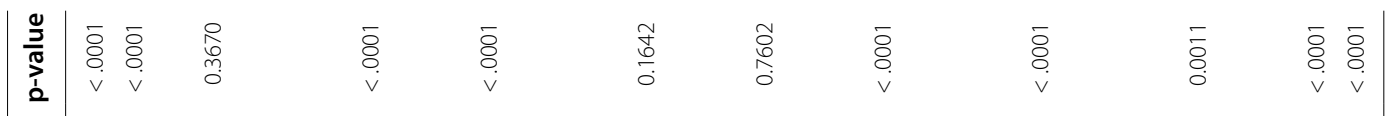

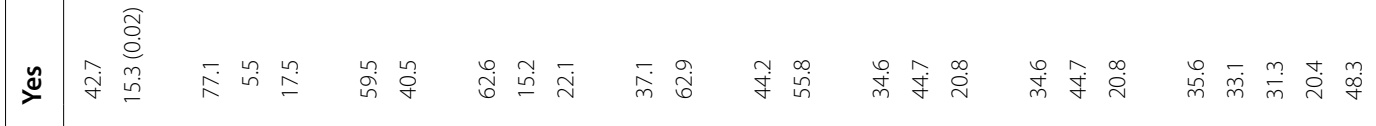

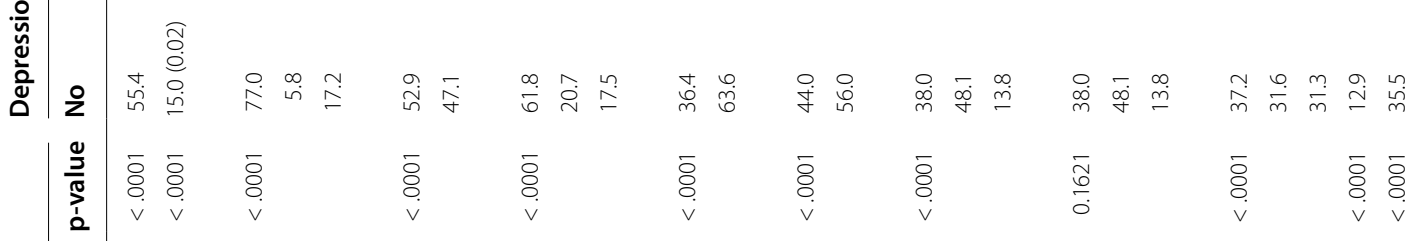

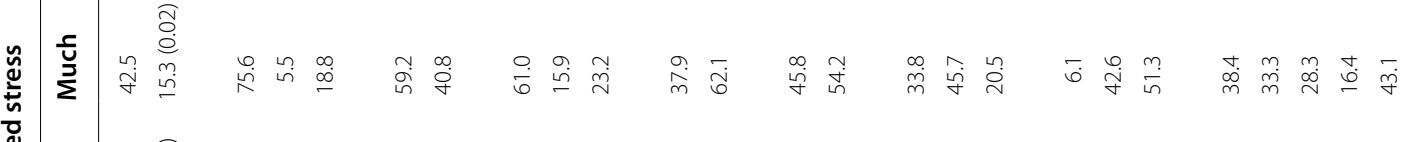

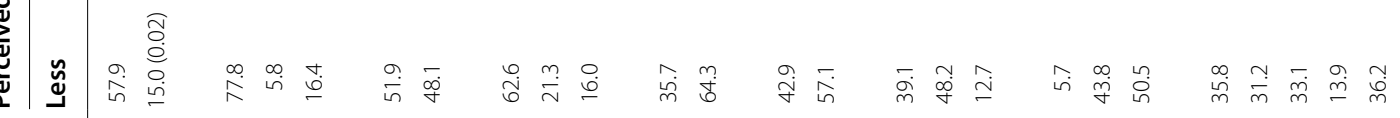

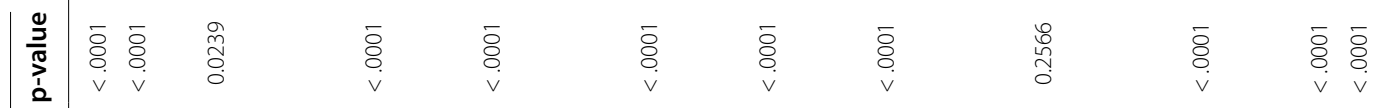

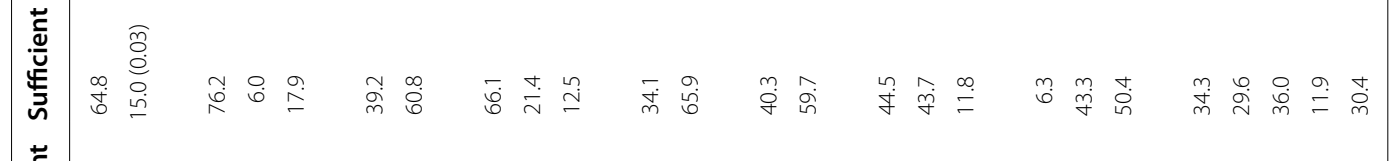
至

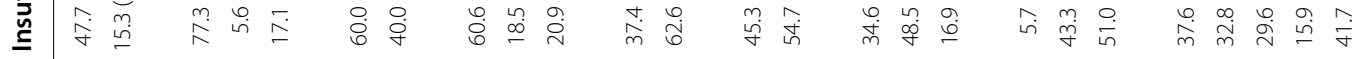

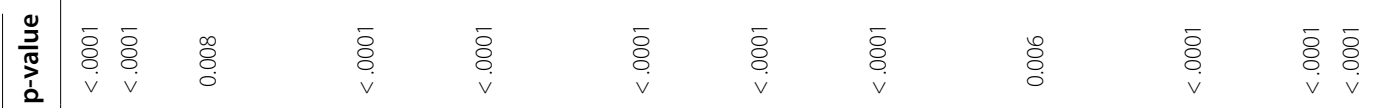

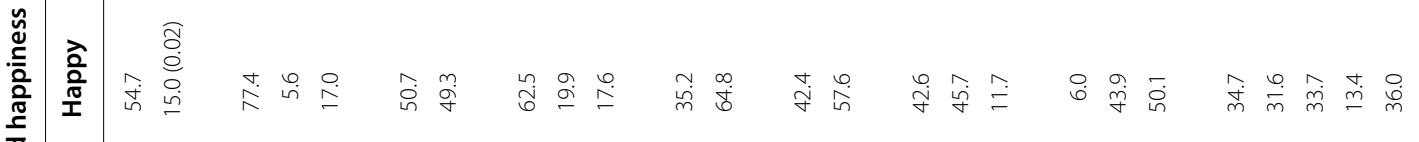

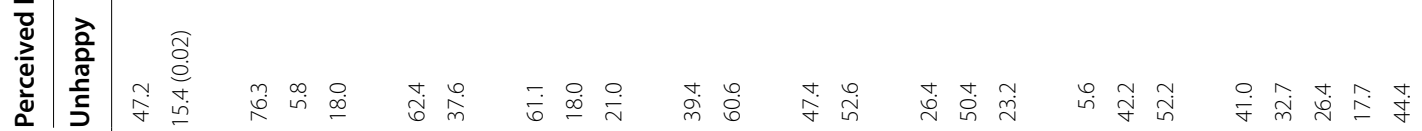

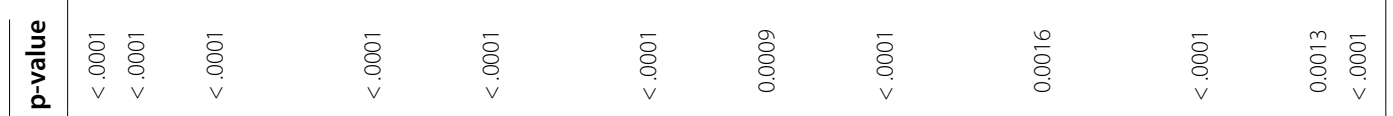
च

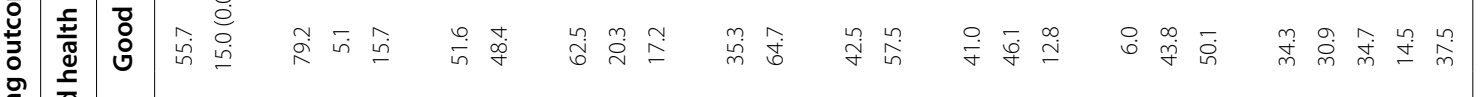

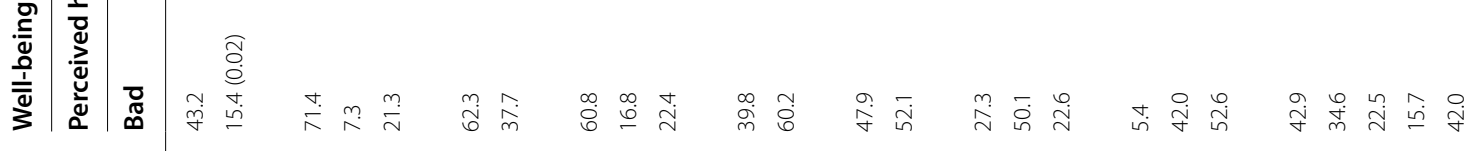

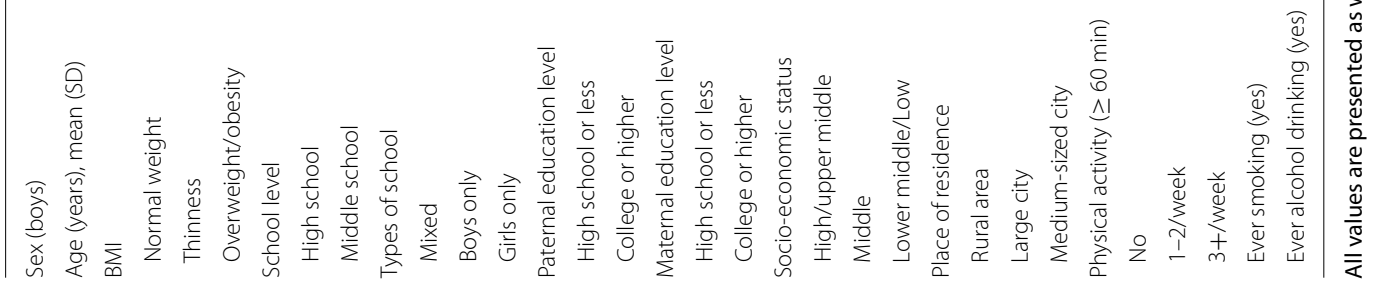


Recent meta-analyses confirmed an inverse association of healthy dietary patterns $[49,50]$ with poor mental health outcomes, like depression in adults. However, the findings in adolescents remained inconsistent. In agreement with previous studies [1-3, 9-25], this study found that healthy dietary behaviours (regular fruit, vegetable, breakfast, and milk consumption) were negatively associated with perceived stress and depression symptoms, despite no linear associations of consumption of fruit, vegetable, and milk. A population-based study among Swiss people aged $15+$ years showed those fulfilling the 5-a-day fruit and vegetable consumption had lower odds of being highly or moderately distressed than individuals consuming less fruit and vegetables $(\mathrm{OR}=0.82$ for moderate distress, and OR $=0.55$, for high distress compared to low distress) [31]. It is possible that due to the consumption of fruits and vegetables, being rich in antioxidants, folic acid and anti-inflammatory components, human optimism or happiness is enhanced [28] and the development of negative mood or depression symptoms decreased [29].

In agreement with previous studies [8, 24-31, 35] unhealthy dietary behaviours (consumption of soft drinks, caffeine, fast food, sweets and snacks, and skipping breakfast) were associated with low self-rated health, unhappiness, and low sleep satisfaction. Although the association became weaker at three or more times consumption of fast foods, increased unhealthy dietary behaviours were inversely associated with positive wellbeing outcomes, in particular, perceived health and happiness. On the other hand, a dose-response relationship between unhealthy dietary behaviours, such as consumption of soft drinks, highly caffeinated drinks, sweetened drinks, and fast food, and inversely, frequency of breakfast consumption as a health dietary behaviour with depression was observed in this study. These findings are consistent with a prospective Australian adolescents study [51] and a prospective cohort study also showed a positive association of fast food and commercial baked foods with depression in adults [52]. However, in a study among university students in ASEAN countries an inverse dose-response relationship between eating breakfast and sugared coffee/tea and a positive linear association between the consumption of snacks, fast foods, soft drinks and depression symptoms [6]. Although the relationship between sugar consumption and major depression seems to have been confirmed in cross-national observations in Asian countries [53], a study among ASEAN university students has shown an inverse dose-response relationship between sugared coffee/tea consumption and depression symptoms [6]. These findings emphasize the need for further investigations.
Nevertheless, some studies have suggested that an increase in carbohydrate-dense but nutrient-poor foods, such as fast food, sweets and snacks, may be used by individuals to cope with negative mood and elevate mood by increasing brain serotonin levels [42]. Several other studies among adolescents [54] and young adults [55] also found an association between caffeine consumption and low sleep satisfaction or poor sleep quality. A study among adolescents in Germany suggested that later bed and rise times were associated with increased consumption of caffeinated drinks and fast food [56]. The biological mechanism to explain this includes that caffeine increases alertness and increased energy as a function of its interactions with adenosine receptors in the brain [57]. However, caffeine use seems to only reduce sleep quality in individuals that are sensitive to the adenosine effects of caffeine [58]. In addition, the German study reported reduced consumption of dairy products was also associated with later bed and rise times [56]. Our study findings supported this study by showing that frequent milk consumption (once per day or more) was associated with sufficient sleep satisfaction. Further, as the practice of skipping breakfast may increase poor sleep quality [30], our study also showed a positive association between regular breakfast consumption and sleep satisfaction. In terms of fast foods, less frequent consumption of fast foods (less than once per day) showed an inverse association, but among those having once per day or more fast foods the association disappeared. This study may lead to a need for a prospective study to examine the causality, since strong relationships with a dose-response relationship between healthy dietary behaviours and well-being parameters and between unhealthy dietary behaviours and mental distress were found.

\section{Study limitations}

The cross-sectional design does not explain if positive well-being promotes a healthier dietary behaviour or healthier dietary patterns lead to more positive wellbeing. Some of the concepts assessed in this study used single item measures such as depression symptoms, happiness and perceived stress, and future studies should include multiple item measures to assess key concepts. Despite the limitations, the inclusion of data from 65,528 adolescents from a nationally representative sample in South Korea supports the external validity of the study results.

\section{Conclusions}

In a large nationally representative sample of adolescent in Korea, strong cross-sectional evidence was found that increased unhealthier dietary behaviour was associated with higher mental distress, while healthier dietary 


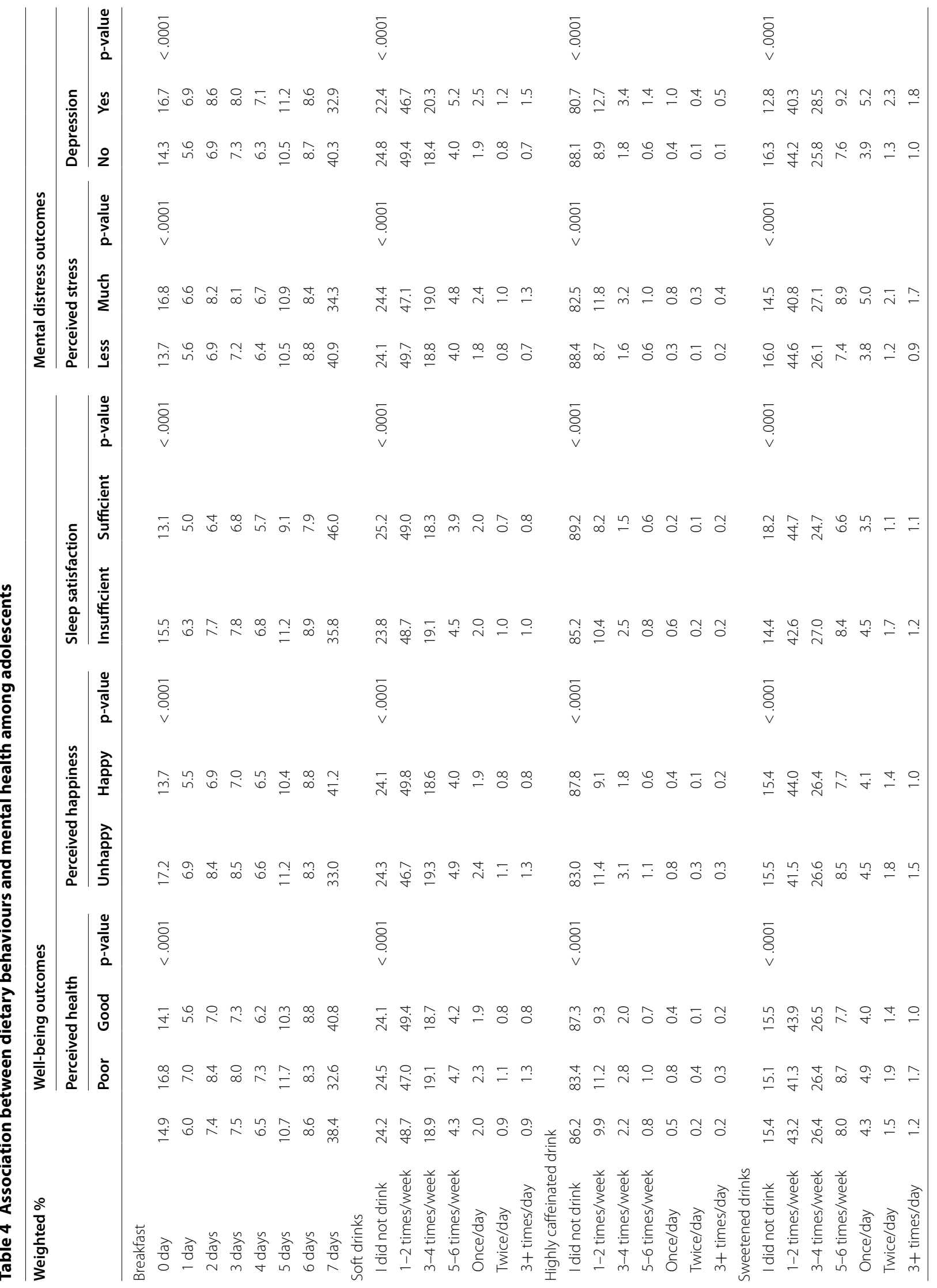




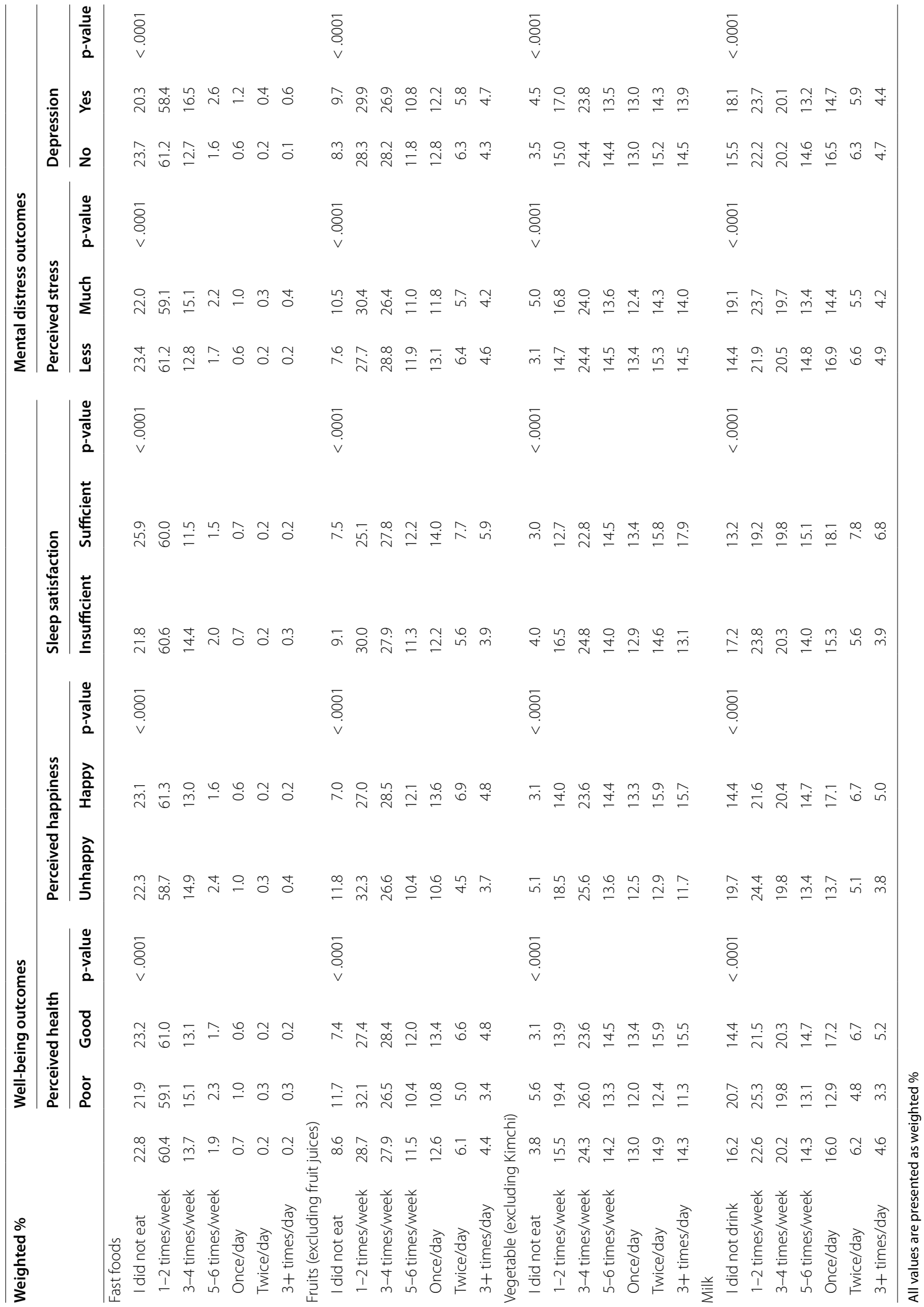


Table 5 Adjusted odds ratios of well-being and mental distress indicators in relation to dietary behaviours among adolescents

\begin{tabular}{|c|c|c|c|c|c|c|c|c|c|c|}
\hline & \multicolumn{6}{|c|}{ Well-being outcomes } & \multicolumn{4}{|c|}{ Mental distress outcomes } \\
\hline & \multicolumn{2}{|c|}{$\begin{array}{l}\text { Perceived health } \\
\text { (healthy) }\end{array}$} & \multicolumn{2}{|c|}{$\begin{array}{l}\text { Perceived happiness } \\
\text { (happy) }\end{array}$} & \multicolumn{2}{|c|}{$\begin{array}{l}\text { Sleep satisfaction (suf- } \\
\text { ficient) }\end{array}$} & \multicolumn{2}{|c|}{$\begin{array}{l}\text { Perceived stress } \\
\text { (much) }\end{array}$} & \multicolumn{2}{|c|}{ Depression (yes) } \\
\hline & $\mathrm{aOR}^{1)}$ & $(95 \% \mathrm{Cl})$ & $\mathrm{aOR}^{1)}$ & $(95 \% \mathrm{Cl})$ & $\mathrm{aOR}^{2)}$ & $(95 \% \mathrm{Cl})$ & $\mathrm{aOR}^{2)}$ & $(95 \% \mathrm{Cl})$ & $\mathrm{aOR}^{3)}$ & $(95 \% \mathrm{Cl})$ \\
\hline \multicolumn{11}{|l|}{ Dietary behaviors } \\
\hline \multicolumn{11}{|l|}{ Breakfast } \\
\hline 0 day & 1.00 & & 1.00 & & 1.00 & & 1.00 & & 1.00 & \\
\hline 1 day & 0.95 & $(0.85-1.05)$ & 1.01 & $(0.92-1.11)$ & 0.96 & $(0.85-1.09)$ & 0.91 & $(0.83-1.00)$ & 0.97 & $(0.89-1.06)$ \\
\hline 2 days & 1.04 & $(0.95-1.14)$ & 1.06 & $(0.97-1.15)$ & 0.99 & $(0.89-1.11)$ & 0.95 & $(0.87-1.04)$ & 1.02 & $(0.94-1.10)$ \\
\hline 3 days & 1.06 & $(0.97-1.17)$ & 1.02 & $(0.94-1.11)$ & 1.12 & $(1.01-1.25)$ & 0.91 & $(0.84-0.99)$ & 0.88 & $(0.82-0.96)$ \\
\hline 4 days & 0.98 & $(0.89-1.08)$ & 1.22 & $(1.11-1.34)$ & 0.99 & $(0.88-1.11)$ & 0.83 & $(0.76-0.92)$ & 0.94 & $(0.87-1.02)$ \\
\hline 5 days & 1.01 & $(0.94-1.10)$ & 1.16 & $(1.07-1.25)$ & 0.99 & $(0.91-1.09)$ & 0.85 & $(0.79-0.91)$ & 0.89 & $(0.83-0.96)$ \\
\hline 6 days & 1.22 & $(1.12-1.34)$ & 1.30 & $(1.19-1.42)$ & 1.13 & $(1.03-1.23)$ & 0.76 & $(0.70-0.82)$ & 0.86 & $(0.79-0.93)$ \\
\hline 7 days & 1.34 & $(1.25-1.43)$ & 1.42 & $(1.34-1.51)$ & 1.45 & $(1.35-1.56)$ & 0.74 & $(0.70-0.78)$ & 0.76 & $(0.72-0.81)$ \\
\hline \multicolumn{11}{|l|}{ Soft drinks } \\
\hline I did not drink & 1.00 & & 1.00 & & 1.00 & & 1.00 & & 1.00 & \\
\hline 1-2 times/week & 1.04 & $(0.99-1.09)$ & 1.08 & $(1.03-1.13)$ & 0.90 & $(0.86-0.96)$ & 0.97 & $(0.93-1.02)$ & 1.05 & $(1.00-1.09)$ \\
\hline 3-4 times/week & 0.90 & $(0.84-0.96)$ & 0.95 & $(0.89-1.01)$ & 0.77 & $(0.72-0.82)$ & 1.07 & $(1.01-1.14)$ & 1.24 & $(1.17-1.31)$ \\
\hline 5-6 times/week & 0.83 & $(0.74-0.92)$ & 0.82 & $(0.74-0.91)$ & 0.70 & $(0.62-0.80)$ & 1.39 & $(1.25-1.54)$ & 1.44 & $(1.31-1.58)$ \\
\hline Once/day & 0.73 & $(0.63-0.84)$ & 0.76 & $(0.66-0.88)$ & 0.77 & $(0.65-0.91)$ & 1.47 & $(1.28-1.70)$ & 1.57 & $(1.38-1.79)$ \\
\hline Twice/day & 0.63 & $(0.50-0.79)$ & 0.77 & $(0.62-0.94)$ & 0.58 & $(0.44-0.77)$ & 1.41 & $(1.12-1.78)$ & 1.59 & $(1.34-1.89)$ \\
\hline $3+$ times/day & 0.63 & $(0.50-0.78)$ & 0.67 & $(0.53-0.84)$ & 0.80 & $(0.63-1.01)$ & 1.75 & $(1.41-2.18)$ & 2.07 & $(1.75-2.44)$ \\
\hline \multicolumn{11}{|c|}{ Highly caffeinated drink } \\
\hline I did not drink & 1.00 & & 1.00 & & 1.00 & & 1.00 & & 1.00 & \\
\hline 1-2 times/week & 0.77 & $(0.72-0.83)$ & 0.73 & $(0.69-0.78)$ & 0.68 & $(0.63-0.73)$ & 1.50 & $(1.42-1.60)$ & 1.50 & $(1.42-1.59)$ \\
\hline 3-4 times/week & 0.65 & $(0.57-0.74)$ & 0.55 & $(0.49-0.62)$ & 0.56 & $(0.48-0.66)$ & 2.22 & $(1.96-2.52)$ & 1.91 & $(1.71-2.13)$ \\
\hline 5-6 times/week & 0.58 & $(0.46-0.73)$ & 0.55 & $(0.44-0.68)$ & 0.70 & $(0.53-0.92)$ & 1.96 & $(1.58-2.44)$ & 2.66 & $(2.19-3.23)$ \\
\hline Once/day & 0.44 & $(0.33-0.58)$ & 0.43 & $(0.34-0.55)$ & 0.40 & $(0.27-0.58)$ & 3.43 & $(2.67-4.41)$ & 2.62 & $(2.15-3.20)$ \\
\hline Twice/day & 0.30 & $(0.19-0.45)$ & 0.42 & $(0.26-0.69)$ & 0.49 & $(0.26-0.96)$ & 3.49 & $(2.28-5.34)$ & 3.57 & $(2.38-5.34)$ \\
\hline $3+$ times/day & 0.39 & $(0.25-0.62)$ & 0.43 & $(0.28-0.68)$ & 0.77 & $(0.45-1.32)$ & 3.01 & $(1.85-4.89)$ & 3.25 & $(2.24-4.71)$ \\
\hline \multicolumn{11}{|l|}{ Sweetened drinks } \\
\hline I did not drink & 1.00 & & 1.00 & & 1.00 & & 1.00 & & 1.00 & \\
\hline 1-2 times/week & 1.01 & $(0.95-1.07)$ & 1.06 & $(1.00-1.12)$ & 0.87 & $(0.82-0.93)$ & 0.99 & $(0.94-1.05)$ & 1.12 & $(1.06-1.18)$ \\
\hline 3-4 times/week & 0.92 & $(0.86-0.99)$ & 0.99 & $(0.93-1.06)$ & 0.77 & $(0.71-0.83)$ & 1.14 & $(1.07-1.21)$ & 1.34 & $(1.26-1.41)$ \\
\hline 5-6 times/week & 0.80 & $(0.73-0.87)$ & 0.95 & $(0.87-1.03)$ & 0.63 & $(0.57-0.71)$ & 1.30 & $(1.21-1.41)$ & 1.45 & $(1.35-1.57)$ \\
\hline Once/day & 0.77 & $(0.69-0.86)$ & 0.94 & $(0.84-1.05)$ & 0.66 & $(0.59-0.75)$ & 1.47 & $(1.33-1.62)$ & 1.58 & $(1.44-1.73)$ \\
\hline Twice/day & 0.65 & $(0.54-0.78)$ & 0.81 & $(0.69-0.94)$ & 0.57 & $(0.47-0.69)$ & 1.82 & $(1.55-2.14)$ & 2.04 & $(1.76-2.37)$ \\
\hline $3+$ times/day & 0.58 & $(0.48-0.70)$ & 0.68 & $(0.57-0.82)$ & 0.82 & $(0.66-1.01)$ & 2.08 & $(1.73-2.50)$ & 1.97 & $(1.67-2.32)$ \\
\hline \multicolumn{11}{|l|}{ Fast foods } \\
\hline I did not eat & 1.00 & & 1.00 & & 1.00 & & 1.00 & & 1.00 & \\
\hline 1-2 times/week & 0.97 & $(0.92-1.02)$ & 1.05 & $(1.01-1.11)$ & 0.85 & $(0.81-0.90)$ & 1.01 & $(0.96-1.05)$ & 1.08 & $(1.04-1.13)$ \\
\hline 3-4 times/week & 0.80 & $(0.75-0.86)$ & 0.89 & $(0.83-0.95)$ & 0.66 & $(0.62-0.72)$ & 1.24 & $(1.16-1.32)$ & 1.43 & $(1.35-1.52)$ \\
\hline 5-6 times/week & 0.69 & $(0.59-0.81)$ & 0.71 & $(0.61-0.82)$ & 0.70 & $(0.59-0.84)$ & 1.49 & $(1.28-1.72)$ & 1.80 & $(1.58-2.05)$ \\
\hline Once/day & 0.50 & $(0.40-0.63)$ & 0.52 & $(0.42-0.66)$ & 0.78 & $(0.58-1.04)$ & 2.03 & $(1.63-2.54)$ & 2.30 & $(1.90-2.78)$ \\
\hline Twice/day & 0.41 & $(0.25-0.69)$ & 0.50 & $(0.31-0.82)$ & 0.58 & $(0.33-1.02)$ & 2.14 & $(1.35-3.39)$ & 2.36 & $(1.66-3.37)$ \\
\hline $3+$ times/day & 1.32 & $(0.67-2.59)$ & 0.73 & $(0.42-1.25)$ & 0.61 & $(0.32-1.19)$ & 2.09 & $(1.24-3.52)$ & 3.57 & $(2.62-4.87)$ \\
\hline \multicolumn{11}{|c|}{ Fruits (excluding fruit juices) } \\
\hline I did not eat & 1.00 & & 1.00 & & 1.00 & & 1.00 & & 1.00 & \\
\hline 1-2 times/week & 1.32 & $(1.21-1.43)$ & 1.45 & $(1.34-1.57)$ & 1.08 & $(0.98-1.18)$ & 0.77 & $(0.72-0.83)$ & 0.88 & $(0.83-0.94)$ \\
\hline
\end{tabular}


Table 5 continued

\begin{tabular}{|c|c|c|c|c|c|c|c|c|c|c|}
\hline & \multicolumn{6}{|c|}{ Well-being outcomes } & \multicolumn{4}{|c|}{ Mental distress outcomes } \\
\hline & \multicolumn{2}{|c|}{$\begin{array}{l}\text { Perceived health } \\
\text { (healthy) }\end{array}$} & \multicolumn{2}{|c|}{$\begin{array}{l}\text { Perceived happiness } \\
\text { (happy) }\end{array}$} & \multicolumn{2}{|c|}{$\begin{array}{l}\text { Sleep satisfaction (suf- } \\
\text { ficient) }\end{array}$} & \multicolumn{2}{|c|}{$\begin{array}{l}\text { Perceived stress } \\
\text { (much) }\end{array}$} & \multicolumn{2}{|c|}{ Depression (yes) } \\
\hline & $\mathrm{aOR}^{1)}$ & $(95 \% \mathrm{Cl})$ & $\mathrm{aOR}^{1)}$ & $(95 \% \mathrm{Cl})$ & $\mathrm{aOR}^{2)}$ & $(95 \% \mathrm{Cl})$ & $\mathrm{aOR}^{2)}$ & $(95 \% \mathrm{Cl})$ & $\mathrm{aOR}^{3)}$ & $(95 \% \mathrm{Cl})$ \\
\hline 3-4 times/week & 1.58 & $(1.46-1.72)$ & 1.76 & $(1.62-1.90)$ & 1.23 & $(1.12-1.35)$ & 0.67 & $(0.62-0.72)$ & 0.83 & $(0.77-0.88)$ \\
\hline 5-6 times/week & 1.61 & $(1.46-1.77)$ & 1.77 & $(1.62-1.94)$ & 1.29 & $(1.17-1.42)$ & 0.68 & $(0.63-0.74)$ & 0.83 & $(0.77-0.90)$ \\
\hline Once/day & 1.80 & $(1.64-1.98)$ & 2.04 & $(1.86-2.23)$ & 1.42 & $(1.29-1.58)$ & 0.66 & $(0.61-0.71)$ & 0.86 & $(0.79-0.92)$ \\
\hline Twice/day & 1.72 & $(1.54-1.93)$ & 2.18 & $(1.95-2.44)$ & 1.56 & $(1.39-1.75)$ & 0.69 & $(0.62-0.76)$ & 0.86 & $(0.78-0.94)$ \\
\hline $3+$ times/day & 1.81 & $(1.58-2.07)$ & 1.89 & $(1.67-2.14)$ & 1.68 & $(1.49-1.90)$ & 0.70 & $(0.63-0.78)$ & 1.05 & $(0.95-1.17)$ \\
\hline \multicolumn{11}{|c|}{ Vegetable (excluding Kimchi) } \\
\hline I did not eat & 1.00 & & 1.00 & & 1.00 & & 1.00 & & 1.00 & \\
\hline 1-2 times/week & 1.35 & $(1.21-1.51)$ & 1.26 & $(1.12-1.40)$ & 1.01 & $(0.88-1.15)$ & 0.69 & $(0.62-0.77)$ & 0.90 & $(0.82-1.00)$ \\
\hline 3-4 times/week & 1.68 & $(1.51-1.87)$ & 1.49 & $(1.34-1.65)$ & 1.17 & $(1.03-1.32)$ & 0.63 & $(0.57-0.70)$ & 0.79 & $(0.72-0.87)$ \\
\hline 5-6 times/week & 1.90 & $(1.69-2.14)$ & 1.61 & $(1.44-1.80)$ & 1.28 & $(1.12-1.46)$ & 0.62 & $(0.56-0.70)$ & 0.80 & $(0.72-0.88)$ \\
\hline Once/day & 1.93 & $(1.73-2.16)$ & 1.61 & $(1.44-1.81)$ & 1.27 & $(1.11-1.45)$ & 0.62 & $(0.55-0.69)$ & 0.84 & $(0.76-0.93)$ \\
\hline Twice/day & 2.22 & $(1.97-2.49)$ & 1.87 & $(1.67-2.10)$ & 1.35 & $(1.18-1.53)$ & 0.61 & $(0.55-0.68)$ & 0.78 & $(0.70-0.86)$ \\
\hline $3+$ times/day & 2.21 & $(1.97-2.48)$ & 1.96 & $(1.75-2.19)$ & 1.56 & $(1.37-1.77)$ & 0.66 & $(0.59-0.74)$ & 0.83 & $(0.75-0.92)$ \\
\hline \multicolumn{11}{|l|}{ Milk } \\
\hline I did not drink & 1.00 & & 1.00 & & 1.00 & & 1.00 & & 1.00 & \\
\hline 1-2 times/week & 1.15 & $(1.08-1.24)$ & 1.15 & $(1.08-1.22)$ & 1.00 & $(0.93-1.08)$ & 0.84 & $(0.79-0.89)$ & 0.93 & $(0.88-0.98)$ \\
\hline 3-4 times/week & 1.28 & $(1.20-1.36)$ & 1.28 & $(1.20-1.36)$ & 1.09 & $(1.01-1.18)$ & 0.82 & $(0.77-0.87)$ & 0.93 & $(0.88-0.99)$ \\
\hline 5-6 times/week & 1.33 & $(1.23-1.44)$ & 1.32 & $(1.23-1.41)$ & 1.07 & $(0.98-1.16)$ & 0.80 & $(0.75-0.86)$ & 0.89 & $(0.84-0.95)$ \\
\hline Once/day & 1.50 & $(1.39-1.61)$ & 1.41 & $(1.32-1.51)$ & 1.18 & $(1.09-1.28)$ & 0.77 & $(0.72-0.82)$ & 0.90 & $(0.85-0.96)$ \\
\hline Twice/day & 1.48 & $(1.33-1.64)$ & 1.36 & $(1.22-1.51)$ & 1.21 & $(1.10-1.34)$ & 0.83 & $(0.76-0.91)$ & 1.02 & $(0.94-1.11)$ \\
\hline 3+ times/day & 1.54 & $(1.36-1.74)$ & 1.37 & $(1.22-1.53)$ & 1.46 & $(1.31-1.63)$ & 0.90 & $(0.82-1.00)$ & 1.06 & $(0.96-1.17)$ \\
\hline
\end{tabular}

behaviour showed a dose-response relationship with higher psychological well-being. It remains unclear, if a healthier dietary behaviour is the cause or the sequela of a more positive well-being.

\section{Abbreviations}

BMI: Body Mass Index; KYRBS: Korea Youth Risk Behavior Web-based Survey.

\section{Authors' contributions}

All authors contributed to the conception and design of the study. SAH analysed the data. KP and SAH were involved in writing and revision of the manuscript. Both authors read and approved the final manuscript.

\section{Author details}

${ }^{1}$ ASEAN Institute for Health Development, Mahidol University, Salaya, Phutthamonthon, Nakhon Pathom 73170, Thailand. ${ }^{2}$ Institute for Health and Society, Hanyang University, Seoul, Republic of Korea. ${ }^{3}$ Department for Management of Science and Technology Development, Ton Duc Thang University, Ho Chi Minh City, Vietnam. ${ }^{4}$ Faculty of Pharmacy, Ton Duc Thang University, Ho Chi Minh City, Vietnam.

\section{Competing interests}

The authors declare that they have no competing interests.

\section{Availability of data and materials}

Data are available from the Korea Centers for Disease Control and Prevention for Institutional Data Access. The dataset is publicly available via http://yhs. cdc.go.kr. Access to the dataset requires an application process via the official website.
Ethics approval and consent to participate

In the last ethics approval, the study protocol was approved by the "Institutional Review Board of the Korean Centers for Disease Control and Prevention (KCDC)" (2014-06EXP-02-P-A). Prior to the survey, each respondent was asked for written informed consent to participate in the survey.

\section{Publisher's Note}

Springer Nature remains neutral with regard to jurisdictional claims in published maps and institutional affiliations.

Received: 27 June 2017 Accepted: 18 November 2017

Published online: 28 November 2017

References

1. Blanchflower DG, Oswald AJ, Stewart-Brown S. Is psychological wellbeing linked to the consumption of fruit and vegetables? Soc Indic Res. 2013;114(3):785-801. https://doi.org/10.1007/s11205-012-0173-y.

2. Mujcic R, Oswald JA. Evolution of well-being and happiness after increases in consumption of fruit and vegetables. Am J Public Health. 2016;106(8):1504-10. https://doi.org/10.2105/AJPH.2016.303260.

3. Lesani A, Mohammadpoorasl A, Javadi M, Esfeh JM, Fakhari A. Eating breakfast, fruit and vegetable intake and their relation with happiness in college students. Eat Weight Disord. 2016;21(4):645-51. https://doi. org/10.1007/s40519-016-0261-0.

4. Liu X, Yan Y, Li F, Zhang D. Fruit and vegetable consumption and the risk of depression: a meta-analysis. Nutrition. 2016;32(3):296-302. https://doi. org/10.1016/j.nut.2015.09.009. 
5. Khalid S, Williams CM, Reynolds SA. Is there an association between diet and depression in children and adolescents? A systematic review. Br J Nutr. 2016;1 16(12):2097-108. https://doi.org/10.1017/ S0007114516004359.

6. Peltzer K, Pengpid S. dietary behaviors, psychological well-being, and mental distress among University students in ASEAN. Iran J Psychiat Behav Sci. 2017;11(2):e10118. https://doi.org/10.5812/ijpbs.10118.

7. Franckle RL, Falbe J, Gortmaker S, Ganter C, Taveras EM, Land T, Davison KK. Insufficient sleep among elementary and middle school students is linked with elevated soda consumption and other unhealthy dietary behaviors. Prev Med. 2015;74:36-41. https://doi.org/10.1016/j. ypmed.2015.02.007.

8. Katagiri R, Asakura K, Kobayashi S, Suga H, Sasaki S. Low intake of vegetables, high intake of confectionary, and unhealthy eating habits are associated with poor sleep quality among middle-aged female Japanese workers. J Occup Health. 2014;56(5):359-68.

9. Conner TS, Brookie KL, Richardson AC, Polak MA. On carrots and curiosity: eating fruit and vegetables is associated with greater flourishing in daily life. Br J Health Psychol. 2015;20(2):413-27. https://doi.org/10.1111/ bjhp.12113.

10. Lengyel CO, Tate RB, Obirek Blatz AK. The relationships between food group consumption, self-rated health, and life satisfaction of communitydwelling Canadian older men: the Manitoba follow-up study. J Nutr Elder. 2009:28(2):158-73. https://doi.org/10.1080/01639360902950182.

11. Fararouei M, Brown IJ, Akbartabar Toori M, Estakhrian Haghighi R, Jafari J. Happiness and health behaviour in Iranian adolescent girls. J Adolesc. 2013;36(6):1187-92. https://doi.org/10.1016/j.adolescence.2013.09.006.

12. Peltzer K, Pengpid S, Sodi T, Mantilla Toloza SC. Happiness and health behaviours among university students from 24 low, middle and high income countries. J Psychol Afr. 2017;27(1):61-8. https://doi.org/10.1080/ 14330237.2016.1219556.

13. Piqueras JA, Kuhne W, Vera-Villarroel P, van Straten A, Cuijpers P. Happiness and health behaviours in Chilean college students: a cross-sectional survey. BMC Public Health. 2011;11:443. https://doi. org/10.1186/1471-2458-11-443.

14. Peltzer K, Pengpid S. Subjective happiness and health behavior among a sample of university students in India. Soc Behav Personal. 2013:41(6):869-80.

15. Grant N, Wardle J, Steptoe A. The relationship between life satisfaction and health behavior: a cross-cultural analysis of young adults. Int J Behav Med. 2009;16(3):259-68. https://doi.org/10.1007/s12529-009-9032-x.

16. White BA, Horwath CC, Conner TS. Many apples a day keep the blues away-daily experiences of negative and positive affect and food consumption in young adults. Br J Health Psychol. 2013;18(4):782-98. https:// doi.org/10.1111/bjhp.12021.

17. El Ansari W, Berg-Beckhoff G. Nutritional correlates of perceived stress among University Students in Egypt. Int J Environ Res Public Health. 2015;12(11):14164-76. https://doi.org/10.3390/ijerph121114164.

18. Kingsbury M, Dupuis G, Jacka F, Roy-Gagnon MH, McMartin SE, Colman I. Associations between fruit and vegetable consumption and depressive symptoms: evidence from a national Canadian longitudinal survey. J Epidemiol Commun Health. 2016;70(2):155-61. https://doi.org/10.1136/ jech-2015-205858.

19. Kim TH, Choi JY, Lee HH, Park Y. Associations between dietary pattern and depression in Korean adolescent girls. J Pediatr Adolesc Gynecol. 2015;28(6):533-7. https://doi.org/10.1016/j.jpag.2015.04.005.

20. Mikolajczyk RT, El Ansari W, Maxwell AE. Food consumption frequency and perceived stress and depressive symptoms among students in three European countries. Nutr J. 2009;8:31. https://doi. org/10.1186/1475-2891-8-31.

21. Richard A, Rohrmann S, Vandeleur CL, Mohler-Kuo M, Eichholzer M. Associations between fruit and vegetable consumption and psychological distress: results from a population-based study. BMC Psychiatry. 2015;15:213. https://doi.org/10.1186/s12888-015-0597-4.

22. Roohafza H, Sarrafzadegan N, Sadeghi M, Rafieian-Kopaei M, Sajjadi F, Khosravi-Boroujeni $\mathrm{H}$. The association between stress levels and food consumption among Iranian population. Arch Iran Med. 2013;16(3):145-8.

23. Tajik E, Latiffah AL, Awang H, Siti Nur'Asyura A, Chin YS, Azrin Shah $A B$, Patricia Koh CH, Mohd Izudin Hariz CG. Unhealthy diet practice and symptoms of stress and depression among adolescents in Pasir
Gudang, Malaysia. Obes Res Clin Pract. 2016;10(2):114-23. https://doi. org/10.1016/j.orcp.2015.06.001.

24. Papier K, Ahmed F, Lee P, Wiseman J. Stress and dietary behaviour among first-year university students in Australia: sex differences. Nutrition. 2015;31(2):324-30. https://doi.org/10.1016/j.nut.2014.08.004.

25. Chang HH, Nayga RM. Childhood obesity and unhappiness: the influence of soft drinks and fast food consumption. J Happiness Stud. 2009;11(3):261-75. https://doi.org/10.1007/s10902-009-9139-4.

26. Zahedi H, Kelishadi R, Heshmat R, Motlagh ME, Ranjbar SH, Ardalan G, et al. Association between junk food consumption and mental health in a national sample of Iranian children and adolescents: the CASPIANIV study. Nutrition. 2014;30(11-12):1391-7. https://doi.org/10.1016/j. nut.2014.04.014.

27. El Ansari W, Adetunji H, Oskrochi R. Food and mental health: relationship between food and perceived stress and depressive symptoms among university students in the United Kingdom. Cent Eur J Public Health. 2014;22(2):90-7. https://doi.org/10.21101/cejph.a3941.

28. Liu C, Xie B, Chou CP, Koprowski C, Zhou D, Palmer P, et al. Perceived stress, depression and food consumption frequency in the college students of China Seven Cities. Physiol Behav. 2007;92(4):748-54. https:// doi.org/10.1016/j.physbeh.2007.05.068.

29. Moor I, Lampert T, Rathmann K, Kuntz B, Kolip P, Spallek J, et al. Explaining educational inequalities in adolescent life satisfaction: do health behaviour and gender matter? Int J Public Health. 2014;59(2):309-17. https:// doi.org/10.1007/s00038-013-0531-9.

30. Wang L, Qin P, Zhao Y, Duan S, Zhang Q, Liu Y, Hu Y, Sun J. Prevalence and risk factors of poor sleep quality among Inner Mongolia Medical University students: a cross-sectional survey. Psychiatry Res. 2016;244:243-8. https://doi.org/10.1016/j.psychres.2016.04.011.

31. Richard A, Rohrmann S, Vandeleur CL, Mohler-Kuo M, Eichholzer M. Associations between fruit and vegetable consumption and psychological distress: results from a population-based study. BMC Psychiatry. 2015;15:213. https://doi.org/10.1186/s12888-015-0597-4.

32. Kim TH, Choi JY, Lee HH, Park Y. Associations between dietary pattern and depression in Korean adolescent girls. J Pediatr Adolesc Gynecol. 2015;28(6):533-7. https://doi.org/10.1016/j.jpag.2015.04.005.

33. Richards $G$, Smith A. Caffeine consumption and self-assessed stress, anxiety, and depression in secondary school children. J Psychopharmacol. 2015;29(12):1236-47. https://doi.org/10.1177/0269881115612404.

34. Weng TT, Hao JH, Qian QW, Cao H, Fu JL, Sun Y, Huang L, Tao FB. Is there any relationship between dietary patterns and depression and anxiety in Chinese adolescents? Public Health Nutr. 2012;15(4):673-82. https://doi. org/10.1017/S1368980011003077.

35. Liu C, Xie B, Chou CP, Koprowski C, Zhou D, Palmer P, Sun P, Guo Q, Duan $L$, Sun $X$, Anderson Johnson C. Perceived stress, depression and food consumption frequency in the college students of China Seven Cities. Physiol Behav. 2007;92(4):748-54.

36. Hayward J, Jacka FN, Skouteris H, Millar L, Strugnell C, Swinburn BA, Allender S. Lifestyle factors and adolescent depressive symptomatology: associations and effect sizes of diet, physical activity and sedentary behaviour. Aust NZ J Psychiatry. 2016;50(11):1064-73.

37. Takada M, Nishida K, Gondo Y, Kikuchi-Hayakawa H, Ishikawa H, Suda K, Kawai M, Hoshi R, Kuwano Y, Miyazaki K, Rokutan K. Beneficial effects of Lactobacillus casei strain Shirota on academic stress-induced sleep disturbance in healthy adults: a double-blind, randomised, placebo-controlled trial. Benef Microbes. 2017;8(2):153-62. https://doi.org/10.3920/ BM2016.0150.

38. Meyer BJ, Kolanu N, Griffiths DA, Grounds B, Howe PR, Kreis IA. Food groups and fatty acids associated with self-reported depression: an analysis from the Australian National Nutrition and Health Surveys. Nutrition. 2013;29(7-8):1042-7. https://doi.org/10.1016/..nut.2013.02.006.

39. Aizawa E, Tsuji H, Asahara T, Takahashi T, Teraishi T, Yoshida S, Ota M, Koga $\mathrm{N}$, Hattori K, Kunugi H. Possible association of Bifidobacterium and Lactobacillus in the gut microbiota of patients with major depressive disorder. J Affect Disord. 2016;202:254-7. https://doi.org/10.1016/j.jad.2016.05.038.

40. Bellisle F. Effects of diet on behaviour and cognition in children. Br J Nutr. 2004;92(Suppl 2):S227-32.

41. Bamber D, Stokes C, Stephen A. The role of diet in the prevention and management of adolescent depression. Nutr Bull. 2007;32:90-9.

42. Lien L, Lien N, Heyerdahl S, Thoresen M, Bjertness E. Consumption of soft drinks and hyperactivity, mental distress, and conduct problems among 
adolescents in Oslo, Norway. Am J Public Health. 2006;96(10):1815-20 https://doi.org/10.2105/AJPH.2004.059477.

43. Ríos JL, Betancourt J, Pagán I, Fabián C, Cruz SY, González AM, González MJ, Rivera-Soto WT, Palacios C. Caffeinated-beverage consumption and its association with socio-demographic characteristics and self-perceived academic stress in first and second year students at the University of Puerto Rico Medical Sciences Campus (UPRMSC). Puerto Rico Health Sci J. 2013;32:95-100

44. Korea Centers for Disease Control and Prevention. Korea Youth Risk Behavior Web-based Survey (KYRBS). http://yhs.cdc.go.kr. Accessed 1 June 2017.

45. Lee SY, Nam CM, Kim JH, Oh KW, Kim YN, Kang YJ, et al. Development of growth curves and the criteria of obesity in Korean children and adolescents. Final report. Gwacheon: Ministry of Health and Welfare (Korea); 2007.

46. Ministry of Education, Ministry of Health and Welfare, Korea Centers for Disease Control and Prevention. The Twelfth Korea Youth Risk Behavior Web-based Survey 2016. Cheongwon: Korea Centers for Disease Control and Prevention; 2016.

47. Ministry of Education, Ministry of Health and Welfare, Korea Centers for Disease Control and Prevention. The Twelfth Korea Youth Risk Behavior Web-based Survey 2016. Cheongwon: Korea Centers for Disease Control and Prevention; 2016.

48. Hoefelmann LP, Lopes Ada S, Silva KS, Silva SG, Cabral LG, Nahas MV. Lifestyle, self-reported morbidities, and poor sleep quality among Brazilian workers. Sleep Med. 2012;13(9):1198-201. https://doi.org/10.1016/j. sleep.2012.05.009

49. Lai JS, Hiles S, Bisquera A, Hure AJ, McEvoy M, Attia J. A systematic review and meta-analysis of dietary patterns and depression in communitydwelling adults. Am J Clin Nutr. 2014;99(1):181-97.
50. Psaltopoulou T, Sergentanis TN, Panagiotakos DB, Sergentanis IN, Kosti $R$, Scarmeas N. Mediterranean diet, stroke, cognitive impairment, and depression: a meta-analysis. Ann Neurol. 2013;74(4):580-91.

51. Jacka FN, Kremer PJ, Berk M, et al. A prospective study of diet quality and mental health in adolescents. PLoS ONE. 2011;6(9):e24805.

52. Sánchez-Villegas A, Toledo E, De Irala J, et al. Fast-food and commercial baked goods consumption and the risk of depression. Public Health Nutr. 2012;15(3):424-32.

53. Westover AN, Marangell LB. A cross-national relationship between sugar consumption and major depression? Depress Anxiety. 2002;16(3):118-20. https://doi.org/10.1002/da.10054

54. Galland BC, Gray AR, Penno J, Smith C, Lobb C, Taylor RW. Gender differences in sleep hygiene practices and sleep quality in New Zealand adolescents aged 15-17 years. Sleep Health. 2017;3(2):77-83. https://doi. org/10.1016/j.sleh.2017.02.001.

55. Lohsoonthorn V, Khidir H, Casillas G, Lertmaharit S, Tadesse MG, Pensuksan WC, Rattananupong T, Gelaye B, Williams MA. Sleep quality and sleep patterns in relation to consumption of energy drinks, caffeinated beverages, and other stimulants among Thai college students. Sleep Breath. 2013;17(3):1017-28. https://doi.org/10.1007/s11325-012-0792-1.

56. Fleig D, Randler C. Association between chronotype and diet in adolescents based on food logs. Eat Behav. 2009:10(2):115-8. https://doi. org/10.1016/j.eatbeh.2009.03.002.

57. Bjorness TE, Greene RW. Adenosine and sleep. Curr Neuropharmacol. 2009;7(3):238-45

58. Landolt HP."No Thanks, Coffee Keeps Me Awake": individual caffeine sensitivity depends on ADORA2A Genotype. Sleep. 2012;35(7):899-900.

\section{Submit your next manuscript to BioMed Central and we will help you at every step:}

- We accept pre-submission inquiries

- Our selector tool helps you to find the most relevant journal

- We provide round the clock customer support

- Convenient online submission

- Thorough peer review

- Inclusion in PubMed and all major indexing services

- Maximum visibility for your research

Submit your manuscript at www.biomedcentral.com/submit
O Biomed Central 